\title{
The Evolution of Flow-Diverting Stents for Cerebral Aneurysms; Historical Review, Modern Application, Complications, and Future Direction
}

\author{
Dong-Seong Shin, ${ }^{1}$ Christopher P. Carroll, ${ }^{2,3}$ Mohammed Elghareeb, ${ }^{4}$ Brian L. Hoh, ${ }^{5}$ Bum-Tae Kim ${ }^{1}$ \\ Department of Neurosurgery, Soonchunhyang University Bucheon Hospital, Bucheon, Korea \\ Department of Brain \& Spine Surgery, ${ }^{2}$ Naval Medical Center Portsmouth, Portsmouth, VA, USA \\ Department of Surgery, Uniformed Services University, Bethesda, MD, USA \\ Department of Neurosurgery, ${ }^{4}$ South Valley University, Qena, Egypt \\ Department of Neurosurgery, ${ }^{5}$ University of Florida, Gainesville, FL, USA
}

In spite of the developing endovascular era, large $(15-25 \mathrm{~mm})$ and giant $(>25 \mathrm{~mm}$ ) wide-neck cerebral aneurysms remained technically challenging. Intracranial flow-diverting stents (FDS) were developed to address these challenges by targeting aneurysm hemodynamics to promote aneurysm occlusion. In 2011, the first FDS approved for use in the United States market. Shortly thereafter, the Pipeline of Uncoilable or Failed Aneurysms (PUFS) study was published demonstrating high efficacy and a similar complication profile to other intracranial stents. The initial FDA instructions for use (IFU) limited its use to patients 22 years old or older with wide-necked large or giant aneurysms of the internal carotid artery (ICA) from the petrous segment to superior hypophyseal artery/ophthalmic segment. Expanded IFU was tested in the Prospective Study on Embolization of Intracranial Aneurysms with PipelineTM Embolization Device (PREMIER) trial. With further post-approval clinical data, the United States FDA expanded the IFU to include patients with small or medium, wide-necked saccular or fusiform aneurysms from the petrous ICA to the ICA terminus. However, IFU is more restrictive in South Korea than in United States. Several systematic reviews and meta-analyses have sought to evaluate the overall efficacy of FDS for the treatment of cerebral aneurysms and consistently identify FDS as an effective technique for the treatment of aneurysms broadly with complication rates similar to other traditional techniques. A growing body of literature has demonstrated high efficacy of FDS for small aneurysms; distal artery aneurysms; non-saccular aneurysms posterior circulation aneurysms and complication rates similar to traditional techniques. In the short interval since the Pipeline Embolization Device was first introduced, FDS has been firmly entrenched as a powerful tool in the endovascular armamentarium. As new FDS are developed, established FDS are refined, and delivery systems are improved the uses for FDS will only expand further. Researchers continue to work to optimize the mechanical characteristics of the FDS themselves, aiming to optimize deploy ability and efficacy. With expanded use for small to medium aneurysms and posterior circulation aneurysms, FDS technology is firmly entrenched as a powerful tool to treat challenging aneurysms, both primarily and as an adjunct to coil embolization. With the aforementioned advances, the ease of FDS deployment will improve and complication rates will be further minimized. This will only further establish FDS deployment as a key strategy in the treatment of cerebral aneurysms.

Kew Words : Endovascular procedure $\cdot$ Intracranial aneurysm $\cdot$ Stents.

- Received : February 11, 2020 • Revised : February 17, 2020 •Accepted : February 19, 2020

- Address for reprints : Brian L. Hoh

Department of Neurosurgery, University of Florida, Gainesville, FL 32611, USA

Tel : +1-352-265-0111, E-mail : brian.hoh@neurosurgery.ufl.edu, ORCID : https://orcid.org/0000-0002-4997-4469

Bum-Tae Kim

Department of Neurosurgery, Soonchunhyang University Bucheon Hospital, 170 Jomaru-ro, Bucheon 14584, Korea

Tel : +82-32-621-5289, Fax : +82-32-621-5107, E-mail : bumtkim@schmc.ac.kr, ORCID : http://orcid.org/0000-0003-2646-8165

This is an Open Access article distributed under the terms of the Creative Commons Attribution Non-Commercial License (http://creativecommons.org/licenses/by-nc/4.0) which permits unrestricted non-commercial use, distribution, and reproduction in any medium, provided the original work is properly cited. 


\section{DEVELOPMENT OF FLOW-DIVERTING STENTS (FDS)}

Following development of the detachable microcoil by Guido Guglielmi in the early 1990s and its subsequent United States Food and Drug Administration (FDA) approval in 1995, endovascular coil embolization of cerebral aneurysms spread throughout the world ${ }^{49-511}$. Adoption of Guglielmi microcoil embolization represented a paradigm shift in the neurosurgical treatment of cerebral aneurysms. As endovascular technique evolved, limitations to primary coil embolization spurred parallel development of additional endovascular devices to facilitate treatment of aneurysms not amenable to primary coil embolization. Chief among these were balloon and intracranial stent-assisted techniques that expanded indications for endovascular treatment of cerebral aneurysms $s^{59}$. Despite the development of an entire industry of endovascular microcoil systems; liquid embolic agents; balloon catheters; and intracranial stents to aid coil embolization, large (15-25 $\mathrm{mm}$ ) and giant $(>25 \mathrm{~mm}$ ) wide-neck cerebral aneurysms remained technically challenging ${ }^{81,83,105)}$. Obliteration rates were low and recurrence rates were high following endovascular treatment of these challenging lesions $\mathrm{s}^{39}$. The combination of unsatisfactory results with attempted endovascular techniques and high morbidity with open treatment highlighted the need for a novel solution to treat the most challenging of cerebral aneurysms ${ }^{31)}$.

Early series sought to push the boundaries of stent-assisted coil embolization techniques to achieve more satisfactory clinical and radiographic outcomes ${ }^{11,105)}$. Traditional intracranial stents were designed to facilitate coil embolization. These stents have low metal surface-area coverage and high porosity to maintain both parent vessel and branch vessel patency. Additionally, these stents serve as a buttress supporting the coil mass and were designed with high radial force. While these characteristics support a coil mass, traditional stents remain vulnerable to coil prolapse and technically challenging to deploy across significant curves or tortuous segments. Unfortunately, unacceptably high recurrence rates persisted ${ }^{11,105)}$.

Intracranial FDS were developed to address these challenges by targeting aneurysm hemodynamics to promote aneurysm occlusion-a significant departure from traditional intracranial stent design. This design innovation meant FDS were developed as a single-stent treatment solution for intracranial aneurysms not amenable to traditional coiling and assistedcoiling techniques ${ }^{8,15,85,101,119)}$. To achieve this goal, FDS eschewed high radial force designs to buttress coils in favor of low radial force to promote conformability and navigability in tortuous vessels. Additionally, FDS were woven with increased metal surface-area coverage to promote flow along the parent vessel and decrease flow into the aneurysm while maintaining sufficient porosity to maintain branch vessel and perforator patency. FDS promote aneurysm occlusion by three major mechanisms. First, FDS decrease direct jet blood flow into the aneurysm and promotes laminar flow along the stent in the direction of the parent artery, so-called central diversion ${ }^{24)}$. Next, this central diversion decreases the speed of blood flow within the aneurysm; increases stagnation; and promotes intra-aneurysmal thrombosis. This decreased wall stress and stagnant flow results in aneurysm remodeling that ultimately promotes endothelialization across the aneurysm neck and arterial reconstruction ${ }^{24,42,98,102)}$.

The Pipeline Embolization Device (PED) (Medtronic, Irvine, CA, USA) was granted FDA approval in 2011, the first FDS approved for use in the United States market ${ }^{114}$. Shortly thereafter, the Pipeline of Uncoilable or Failed Aneurysms (PUFS) study was published demonstrating high efficacy and a similar complication profile to other intracranial stents ${ }^{3,5)}$. The initial FDA instructions for use (IFU) were limited to adult patients with the wide-neck, large or giant aneurysms between the petrous and ophthalmic segments of the internal carotid artery (ICA) ${ }^{114}$. With published reports of safe off label use for aneurysms beyond the petrous to ophthalmic ICA and development of second generation FDS, the IFU has since expanded to small $(<7 \mathrm{~mm})$ and medium $(7-15 \mathrm{~mm})$, wide neck aneurysms of the entire intracranial ICA. To date, safe off-label use has been reported for cerebral aneurysms in most cerebrovascular territories with a parent vessel diameter of $2-5 \mathrm{~mm}^{6,9,10,16,18,21,26,47,73,94,107,120,121)}$.

\section{CHARACTERISTICS OF FDS}

As the world's first FDS, the PED has the greatest volume of utilization data in the peer-reviewed literature. The second generation PED, Pipeline Flex Embolization Device (PFED) (Medtronic), was introduced in 2015 and achieved independent FDA approval in 2018. The PFED has now surpassed the 
1st generation PED in clinical practice ${ }^{116)}$. Other FDS like Slik (Balt, Montmorency, France); Surpass (Stryker Neurovascular, Fremont, CA, USA); and the Flow Re-direction Endoluminal Device (FRED) (Microvention, Tustin, CA, USA) were originally developed and available for use in Europe ${ }^{27}$. The Surpass FDS received initial FDA approval in 2018 and post-approval clinical evaluation is currently ongoing with the Surpass Intracranial Aneurysm Embolization System Pivotal trial (SCENT) in large or giant wide-necked aneurysms at 23 centers is the United States ${ }^{80}$. With the exception of the PED/ PFED and Surpass (FDA approved in 2018) ${ }^{115}$ ), other FDS are either not available in United States or actively in the approval process. However, PED/PFED, Surpass, and FRED are approved for use in South Korea.

\section{IFU in United States and South Korea}

The FDA granted initial approval of the PED in 2011 $18,21,98$. The initial FDA IFU limited its use to patients 22 years old or older with wide-necked large or giant aneurysms of the ICA from the petrous segment to superior hypophyseal artery/ ophthalmic segment ${ }^{114)}$. Following approval, many practitioners published series reporting PED safety and efficacy in the off-label treatment of aneurysms that did not meet the widenecked or large, giant aneurysm criteria ${ }^{89}$. With further postapproval clinical data the FDA expanded the IFU to include patients with small or medium, wide-necked (neck $\geq 4 \mathrm{~mm}$ or dome : neck <2) saccular or fusiform aneurysms from the petrous ICA to the ICA terminus ${ }^{116}$. Expanded IFU were tested in the Prospective Study on Embolization of Intracranial Aneurysms with Pipeline ${ }^{\mathrm{TM}}$ Embolization Device (PREMIER) trial ${ }^{53}$. Twenty-two clinical centers participated in the PREMIER trail and enrolled 141 cases of small-medium $(\leq 12 \mathrm{~mm})$, wide-necked ICA aneurysms. The complete occlusion rate (Raymond grade I) was $76.8 \%$ at 12 months with a 30 -day major neurologic morbidity rate (major ipsilateral stroke or neurologic death) of $2.1 \%$. PREMIER trial further validated clinical series of safe off-label use.

Although the PED has been approved for use in South Korea since $2014^{54)}$, IFU are more restrictive in South Korea than in United States. Korea IFU limited its use to patients with only unruptured aneurysm. Aneurysmal diameters have to be over $15 \mathrm{~mm}$. If aneurysmal diameter is less than $15 \mathrm{~mm}$, some requirements have to be fulfilled for FDS use as follows : blister aneurysm on proximal ICA, fusiform aneurysm, or dis- secting aneurysm on vertebral artery. FDS is allowed during procedure only one. If FDS are used during procedure multiple unavoidably, Heath Insurance Review and Assessment (HIRA) Service carry out inspections of medical rationale ${ }^{62)}$. Moreover, use of any detachable coil jointly is not allowed with FDS. Korean neurosurgeons expect Korea IFU of FDS to be changed because PREMIER trial validated clinical series of safe expanded indications and FDA approved of expanding the IFU in United States.

\section{Profiles of FDS}

The PED is a self-expanding, microcatheter guidewire-delivered, braided mesh cylinder constructed of 48 interwoven stands of platinum-tungsten and cobalt-chromium-nickel alloy wire. This design results in 30-35\% metal coverage of the arterial wall surface area. The device is available in diameters from $2.5-5.0 \mathrm{~mm}$ with a deployed diameter up to $0.25 \mathrm{~mm}$ larger than the labelled diameter and lengths of $10-35 \mathrm{~mm}^{43,74)}$. There are not integral radiopaque markers on the PED. Rather, the delivery micro-guidewire has a $15 \mathrm{~mm}$ soft distal tip preceded by a distal radiopaque marker as well as both radiopaque resheathing ("point of no return") and proximal markers. The 2nd generation PFED did not see significant changes to the basic design but did involve substantial revisions to improve the delivery system. These changes made the PFED easier to deliver, particularly around tortuous segments, and easier to resheath ${ }^{76,78,90)}$.

The Surpass Streamline FDS was also designed as a low-porosity mesh tubular structure. In contrast to the PED/PFED, it is composed of cobalt-chromium alloy wires with interwoven radiopaque platinum-tungsten wires for radiopacity integral to the stent. The 3- and 4-mm Surpass FDS are composed of 72 wires compared to 96 wires in the 5-mm Surpass FDS. Increased mesh density increased metal coverage thereby decreasing aneurysm blood flow and producing a more uniform rhomboidal cell density as vessels taper ${ }^{27,34)}$. Additionally, the Surpass FDS is available in lengths up to $50 \mathrm{~mm}$ to reduce the need for multiple devices to cover lesions and the inherent risks associated with the use of multiple overlapping or telescoping FDS. The Surpass FD is unique in that it is preloaded at the distal end of 0.040 inch inner diameter delivery microcatheter ${ }^{112}$.

FRED is unique in that it is composed of a two-layered weave. The 16-strand outer layer functions similar to a tradi- 
tional low metal coverage stent while the 48-strand inner nitinol layer functions as a FDS. The stent has several integral radiopaque markers with four markers on each end of the outer stent and two interwoven helical radiopaque wires between the inner and outer layer. FRED is available in diameters from $3.5-5.0 \mathrm{~mm}$ and lengths from $13-55 \mathrm{~mm}$. Due to a $5 \mathrm{~mm}$ overhang of the outer vs. inner layer, the FRED achieves slightly shorter working lengths. This design was theorized to improve both navigability and wall apposition to aid complete aneurysm occlusion, particularly in tortuous parent vessels ${ }^{38,64,75)}$. In an initial series of 34 large or giant wide necked aneurysms in 29 patients, 3- and 6-month complete aneurysm occlusion rates were $56 \%(n=34)$ and $73 \%(n=30)$, respectively ${ }^{81)}$.

\section{GENERAL PROCEDURES}

Preparation for a FDS procedure is very similar to conventional coil embolization or stent-assisted coil embolization techniques for cerebral aneurysms. Differences in technique arise from the larger profile of FDS that necessitates planning for larger guide and intermediate catheters with emphasis on greater proximal support than traditional coil embolization techniques ${ }^{27,29)}$. In general, a large diameter 6- or 7-French (F) guide catheter or shuttle sheath is used proximally in the common carotid artery or ICA. An intermediate support catheter of 5-6 F is often used for added support ${ }^{29,69)}$. The microcathe- ter $(0.027$ inch inner-diameter) will be navigated past the aneurysm over a microwire with the microcatheter left distal to the target aneurysm. Next, the microwire is removed and the FDS is loaded into the microcatheter. Vessel tortuosity and curves make FDS susceptible to the Simmons effect, or paradoxical movement of the catheter. Greater vessel tortuosity lends to greater Simmons effect. This can result in the microcatheter jumping or migrating during FDS delivery. For this reason, we recommend preliminarily deploying the distal portion of stent until the cells fully expand $20 \mathrm{~mm}$ or more distal to the aneurysmal neck. This is usually accomplished by exposing $10-15 \mathrm{~mm}$ of the FDS ${ }^{64,70)}$. The Surpass FDS is preloaded in a $3.7 \mathrm{~F}$ microcatheter, unique versus other systems ${ }^{34)}$. The intermediate catheter must pass across the parent artery of aneurysm neck portion for surpass deployment to facilitate ease of deployment. For all other FDS, once distal FDS is deployed and expanding the microcatheter is drawn back to the predetermined distal landing position.

After this maneuver, FDS deployment can proceed by unsheathing the stent. To do so, the FDS delivery wire is held with slight forward tension while the microcatheter is drawn back. The practitioner can "push" the FDS to promote further expansion and deployment once the FDS distal marker aligns with the distal microcatheter tip. Successful FDS deployment requires a balance between pushing delivery-wire and unsheathing microcatheter from the device. In general, it is ideal that the proximal or "unsheathing" FDS be shaped like a wine
(A)
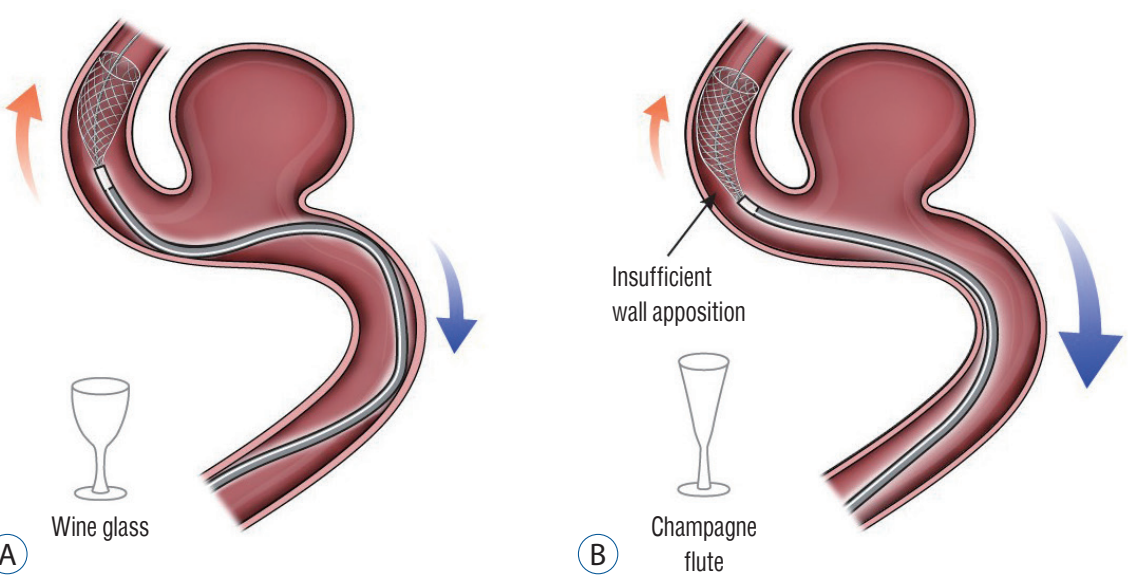

(C)

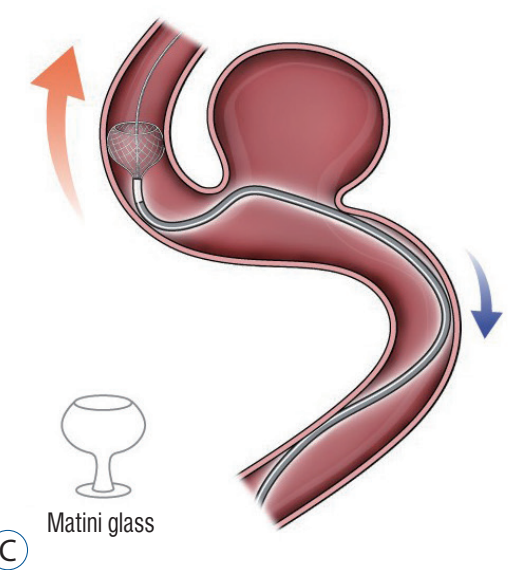

Fig. 1. Successful FDS deployment requires a balance between pushing delivery-wire and unsheathing microcatheter from the device. A It is ideal that the proximal or "unsheathing" FDS be shaped like a wine glass. B : Insufficient forward-loading or aggressive unsheathing can result in cells expanding in the shape of a champagne flute. C : Excessive forward loading of the FDS will result in the expanding FDS cells taking the shape of a martini glass. FDS: flow-diverting stents. 
glass. Insufficient forward-loading or aggressive unsheathing can result in cells expanding in the shape of a champagne flute. In contrast, excessive forward loading of the FDS will result in the expanding FDS cells taking the shape of a martini glass (Fig. 1). Both configurations can be avoided by monitoring cell expansion real time with live fluoroscopy. Good wall apposition is key to successful FDS deployment. However, in many cases this can be difficult to achieve. If insufficient apposition is identified, the push-pull technique can be used to improve deployment against the vessel wall (Fig. 2). After completely deploying the FDS, wall apposition is confirmed by angiography. If wall apposition is insufficient, the practitioner can use conformable intracranial balloons to remodel the stent with good vessel apposition ${ }^{28,33}$ (Fig. 3).

\section{PERIPROCEDURAL ANTIPLATELET TREAT- MENT}

FDS procedures are susceptible to a variety of thromboembolic complications. As such, pre- and post-procedure dual antiplatelet therapy (DAPT) is considered the standard of care for all FDS procedures ${ }^{7,35,40,113)}$. Direct injury of arterial endothelium during FDS deployment can activate the extrinsic pathway and led to intra- or post-procedural thrombosis. Following FDS deployment, altered flow dynamics will persist

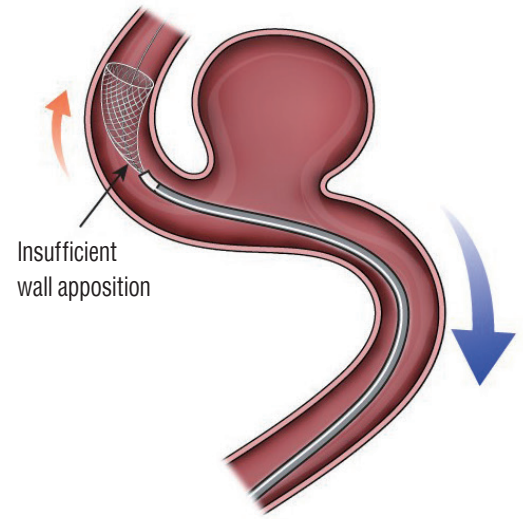

(A) Deploying stent

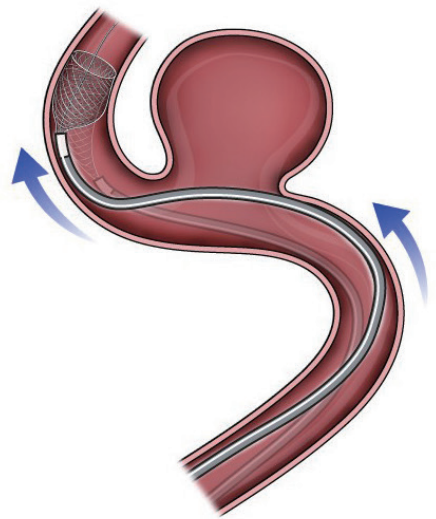

(B) Push

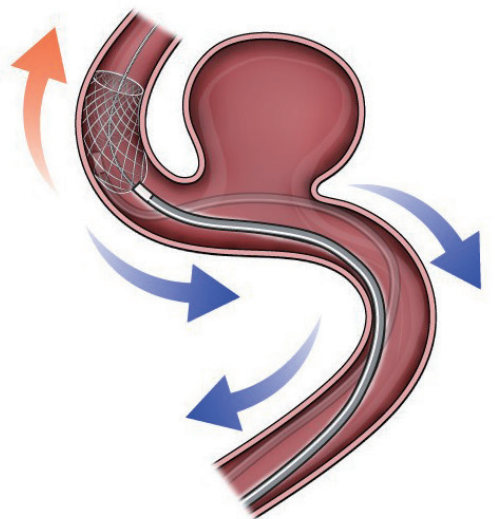

(C)

Fig. 2. If insufficient apposition is identified, the repetitive push-pull technique can be used to improve deployment against the vessel wall. A : Insufficient wall apposition. B : Push technique. C : Pull technique.

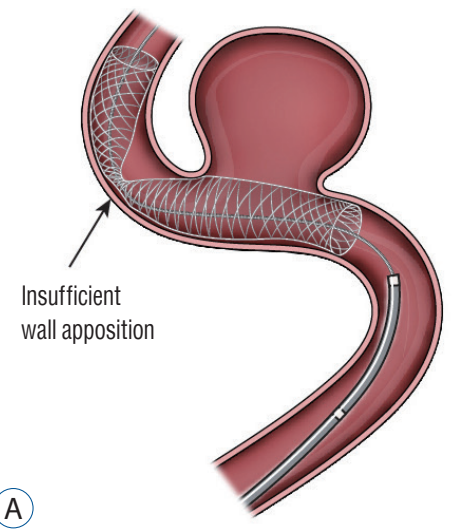

Fig. 3. Conformable intracranial balloons can help to remo angiography. B: Remove micro-guide wire for flow diverter stent and set up the intracranial balloon with micro-guide wire C : Balloon angioplasty for good vessel apposition. 
until neo-endothelialization such that the vessel is at risk of thrombosis at any time up until the stent is fully endothelialized or "healed in"36). Moreover, changes in flow direction, speed, and turbulence are very difficult to predict. In-stent thrombosis or distal embolization can lead to ischemic stroke that ranges from clinically silent to permanent neurologic deficit or death, depending on the arterial territory involved. While the use of DAPT is widely accepted, a variety of dosing regimens exist pre- and post-procedure. A typical protocol would be aspirin $81-325 \mathrm{mg}$ and clopidogrel $75 \mathrm{mg}$ for 5-7 days pre-procedure with or without a loading dose of clopidogrel $^{1)}$. The post-procedural duration of DAPT also is not standardized. Generally, clopidogrel $75 \mathrm{mg}$ is continued for 3-6 months and aspirin 81-325 $\mathrm{mg}$ is continued for a minimum of 6 months ${ }^{113)}$. Clopidogrel resistance is associated with thromboembolic complications in both the cardiac and neuroendovascular literature such that many practitioners use platelet function assays to assess the DAPT response ${ }^{40)}$. In patients not responsive to clopidogrel $75 \mathrm{mg}$ daily, increasing the dose, or a switch to ticagrelor is often employed ${ }^{67)}$. Further research is needed to determine an evidence-based "best" protocol for pre- and post-rpocedure DAPT in FDS deployment and neuroendovascular therapy more broadly.

\section{EFFICACY OF FDS BY ANEURYSM TYPE}

\section{Overall efficacy of FDS}

Several systematic reviews and meta-analyses have sought to evaluate the overall efficacy of FDS for the treatment of cerebral aneurysms. Three large studies reported largely similar results. In 2013, Brinjikji et al. ${ }^{14)}$ reported a meta-analysis of 29 studies representing 1451 patients treated with FDS and found complete occlusion, morbidity and mortality rates of $76 \%, 5 \%$, and 4\%, respectively. Arrese et al. ${ }^{2)}$ analyzed an additional 15 studies including 897 patients and found comparable results : $76.2 \%$ complete occlusion rate; $7.3 \%$ early vs. $2.6 \%$ late morbidity; and 2.8\% early vs. 1.3\% late mortality. More recently in 2015 Briganti et al. ${ }^{12)}$ performed a systematic review of 18 studies of FDS and identified a complete occlusion rate of $81.5 \%$; morbidity rate of $3.5 \%$; and mortality rate of $3.4 \%$. These and other reviews consistently identify FDS as an effective technique for the treatment of aneurysms broadly with complication rates similar to other traditional techniques.

\section{Wide-necked, large and giant aneurysms}

The original indication for the various FDS was widenecked, large or giant aneurysms of the ICA. While the indications for FDS have expanded beyond this original IFU and the use of FDS with traditional coiling techniques has grown, the most developed evidence for FDS efficacy is in this original group of aneurysms ${ }^{89)}$. The PUFS trial is perhaps the most well-known ${ }^{4)}$. PUFS included 180-day follow up of patients undergoing PED deployment PED for unruptured cerebral aneurysms meeting the original FDA IFU. The trial prospectively enrolled 108 patients over an 8 -month period at 10 United States centers. PED were successfully deployed in 99.1\% of patients. Monotherapy with the PED resulted in complete occlusion (Raymond I) in 73.8\%, 86.8\%, and $92.1 \%$ at 6-, 12-, and 36-month angiographic follow-up, respectively with a 5.6\% 180-day major complication rate. Moreover, $97.4 \%$ of treated vessels were free of significant ( $>50 \%)$ stenosis at 3 years angiographic follow-up and there were no additional instances of intracranial hemorrhage between 1 month and 3 years $^{5)}$. The late complication rate at 5 -year follow up was $0 \%{ }^{3)}$. Success of the PUFS trial and its subsequent longterm follow up was a paradigm shift aneurysms treatment. The trial not only validated a novel device, the FDS, but also validated an effective treatment for wide-necked large and giant aneurysm that had been so challenging to treat prior to PUFS ${ }^{46,48,117)}$.

In a similar study, Chalouhi et al. ${ }^{20)}$ compared FDS (40 cases) and coiling (120 cases) for treatment of large ( $>10 \mathrm{~mm})$ unruptured intracranial saccular aneurysm. While there was no significant difference in complication rates (7.5\% vs. $7.5 \%$ ), the FDS group had significantly higher rates of complete aneurysm occlusion on angiographic follow up, $86 \%$ vs. $41 \%$ $(p<0.001)$. Good efficacy of FD in large aneurysm can found other studies. In an evaluation of large cavernous carotid aneurysms, Tanweer et al. ${ }^{111)}$ reported 88.4\% 2-year Raymond I occlusion and $100 \%$ Raymond I or II occlusion at 3-year follow up. In the treatment of cavernous carotid aneurysms there was a $2.3 \%$ major neurologic complication rate and 0 patient deaths. In a slight variation, Chiu et al. ${ }^{23)}$ investigated the efficacy of PED for aneurysms not amenable to coil embolization, defined as neck : $>4 \mathrm{~mm}$; dome/neck ratio $<1.6$; fusiform morphology; and/or size $>10 \mathrm{~mm}$. At 2-year angiographic follow up $93.2 \%$ of aneurysms were completely occluded. Their series reported minor complications in 7.6\% (4.2\% transient 
ischemic attacks; $3.4 \%$ minor stroke) and major complications in $1.6 \%\left(0.8 \%\right.$ major stroke; $0.8 \%$ mortality $^{23)}$. In a similar study, Kim et al. ${ }^{60)}$ reported $77.4 \%$ complete occlusion rate at 2-years for large/giant ( $>15 \mathrm{~mm}$ ) intracranial aneurysms undergoing FDS placement. They reported a $4.4 \%$ procedural morbidity rate and no mortality.

\section{Small and medium-sized aneurysms}

Building on promising data in challenging wide-necked large or giant aneurysms, reports of off-label FDS use for smaller aneurysms not amenable to coil embolization followed. In a multicenter study of 149 small ( $<7 \mathrm{~mm}$ ) unruptured intracranial aneurysms, Griessenauer et al. ${ }^{47)}$ reported complete occlusion in $87 \%$ with a $6 \%$ complication rate. In the same aneurysm cohort, Chalouhi et al. ${ }^{21)}$ reported $85 \%$ Raymond I or II occlusion with a 3\% complication rate among 124 small $(<7 \mathrm{~mm})$ unruptured intracranial aneurysms. Subsequently, Chalouhi et al. ${ }^{18)}$ compared FDS and coiling of aneurysms $<10 \mathrm{~mm}$ and found significantly higher complete occlusion rates with FDS (80\% FDS vs. 70\% coiling) with no significant difference in complication rates (5\% FDS vs. $3 \%$ coiling). In a meta-analysis of 10 studies involving 786 cases of FDS for intracranial aneurysms $<10 \mathrm{~mm}$ Yao et al. ${ }^{121)}$ identified a $84.2 \%$ complete occlusion rate with $5.2 \%$ procedural morbidity. While it remains an off-label use of FDS, a growing body of literature has demonstrated high efficacy of FDS for small aneurysms and complication rates similar to traditional coiling techniques. Furthermore, when compared directly to coiling FDS frequently have higher angiographic occlusion rates. While further evidence is needed to change the IFU, FDS are a viable primary or adjunctive option for small intracranial aneurysms not amenable to traditional coiling techniques alone.

\section{Distal artery aneurysms}

Reports of off-label FDS use have included several reports involving distal artery cerebral aneurysms. As the smallest PED/PFED diameter is $2.5 \mathrm{~mm}$ and the smallest Surpass FDS diameter is $3 \mathrm{~mm}$, the current compliment of FDA-approved FDS generally are not suited to the treatment of distal aneurysms. In addition to restrictive parent vessel diameters, distal arteries are often tortuous and may have more small branch$\mathrm{es}^{73,84)}$. Taken together, these anatomic properties of distal arteries increase the technical demands to deploy the FDS; risk of failed deployment; and risk of complications. Early in the clinical use of FDS, Pistocchi et al. ${ }^{94)}$ reported their experience with FDS in 26 patients with aneurysms of the anterior circulation distal to the ICA terminus. The complete occlusion rate was $82.6 \%$ and permanent neurological complications occurred in $3.7 \%$. Several more recent series of $<30$ cases similarly reported complete occlusion rates of 75-80\% and complication rates of $3.7-13 \% \%^{9,16)}$. In a study focusing on FDS for the treatment of 50 anterior communicating artery complex aneurysms, Colby et al. ${ }^{26)}$ reported complete occlusion rate of $86 \%$ and a complication rate of $6 \%$. For comparison, Sturiale et al. ${ }^{109)}$ reported 20 cases of traditional stent-assisted coil embolization of distal anterior cerebral artery (ACA) aneurysms and experienced a $20 \%$ complication rate. A recent metaanalysis of coil embolization techniques for distal ACA aneurysms reported morbidity and mortality of $15 \%$ and $9 \%$, respectively ${ }^{92)}$. The recent development of low-profile braided FDS and additional design advances in FDS and their delivery systems my make distal artery aneurysm more amenable to this promising technique ${ }^{82)}$.

\section{Non-saccular and posterior circulation aneu- rysms}

Despite advances in both open and endovascular surgical technique, non-saccular fusiform or dissecting aneurysms and posterior circulation aneurysms have remained challenging lesions. The complete occlusion rates for these lesions are lower necessitating frequent staged or revision treatment. And, the complication rates have remained high despite new techniques ${ }^{46,55,104,108)}$. With the advent of FDS and reports of their efficacy in complex ICA lesions, there was natural excitement at the prospect of apply FDS to the treatment of these challenging aneurysms. In a 2015 meta-analysis, Rouchaud et al. ${ }^{99)}$ compared endovascular deconstructive (occlusion aneurysms with parent artery) vs. reconstructive and FDS techniques (only aneurysmal occlusion or remodeling) for the treatment of ruptured blister aneurysms. Evaluating data from 31 studies including 265 procedures there was a significantly higher immediate occlusion rate with deconstructive techniques ( $77.3 \%$ vs. $33.0 \%, p=0.0003)$. However, perioperative risk was significantly higher with deconstructive techniques (29\% vs. $5.0 \%, p=0.04$ ) and the occlusion rates on medium- and long-term follow up were not significantly different $(81.0 \%$ vs. $73.6 \%, p=0.2)$. In a subgroup analysis comparing 
endovascular reconstruction to FDS treatment, there was a significantly higher occlusion rate in the FDS subgroup (90.8\% vs. $67.9 \%, p=0.03)$. Bhogal et al. ${ }^{10)}$ reported their single center experience with FDS in 56 non-saccular posterior circulation aneurysms. Among dolichoectatic aneurysms the complete occlusion rate was $66.6 \%$ while complete occlusion was achieved in $75 \%$ of fusiform aneurysms. By comparison, complete occlusion was achieved in only $17.8 \%$ of vertebrobasilar junction (VBJ) non-saccular aneurysms. While the authors couldn't provide a clear hypothesis why transitional VBJ aneurysms had such poor occlusion rates, they recommended either adjunctive coil embolization or the use of multiple overlapping FDS. Sönmez et al. ${ }^{107)}$ performed a meta-analysis of deconstructive and reconstructive techniques to treat dissecting VBJ aneurysms. Their analysis included 17 studies composed of 478 patients and they found significantly high early $(88.0 \%$ vs. $53.0 \%, p<0.0001)$ and late $(88.1 \%$ vs. $81.0 \%$, $p<0.0001)$ angiographic occlusion with deconstructive techniques. Mortality rates were lower in the reconstructive group (4.0\% vs. $10.0 \%)$ but the difference was not statistically significant. In a single center series of 59 cases, Bender et al. ${ }^{6}$ achieved 78\% complete occlusion using FDS for posterior circulation aneurysms with a $9 \%$ complication rate. These results were somewhat at odds with contemporary case series, but the authors attributed their improved results to a preponderance of posterior circulation aneurysms isolated to the vertebral artery in their series ${ }^{6}$. While efficacy may have been less than traditional techniques, FDS was often associate with a relatively lower complication rate for posterior circulation aneurysms. Given the lower occlusion rates. Further advances in FDS as well improved facility with FDS-assisted coiling and overlapping FDS techniques may facilitate improved obliteration rates, but further clinical data is needed before a revision of IFU to include posterior circulation aneurysms would likely be considered.

\section{COMPARISON OF TECHNIQUES FOR THE ENDO- VASCULAR TREATMENT OF CEREBRAL ANEU- RYSMS}

\section{Coil embolization vs. FDS}

With the expansion of FDS use beyond the large and giant wide-necked aneurysms of the ICA not amenable to coil em- bolization, a comparison can now be made between traditional coil embolization and FDS for treatment of cerebral aneurysms. Petr et al. ${ }^{91)}$ reported their institutional series of endovascular treatment of 310 patients with aneurysms of varied size and locations. Treatment modalities included both coil embolization and FDS. While the FDS group had a significantly larger mean aneurysm size $(12.3 \mathrm{~mm}$ vs. $8.3 \mathrm{~mm}$, $p<0.001)$, there was no significant difference in complication rates. Furthermore, complete angiographic occlusion was significantly higher in the FDS group (56.6\% vs. $49.0 \%, p<0.001$ ) while revision treatment was significant more common in the coil embolization group ( $14.8 \%$ vs. $5.7 \%, p=0.009)$. In their comparison of coil embolization and FDS techniques, Di Maria et al. ${ }^{37)}$ also found significantly higher complete occlusion rates with FDS (85.3\% vs. 58.3\%, $p=0.019)$. Colby et al. $\left.{ }^{30}\right)$ sought to evaluate radiation dose in large or giant ICA aneurysms treated with coiling or FDS. They found the FDS group had significantly lower patient dose; fluoroscopy time; and procedural contrast use. Kim et al. ${ }^{61)}$ reported their institutional series of complex unruptured cavernous and paraclinoid aneurysms. Treatment modalities included coil embolization, FDS, clip obliteration, cerebral bypass for flow reversal, and parent artery sacrifice. Raymond I or II occlusion was achieved in $90 \%$ of coiled aneurysms vs. 95\% for FDS; $96 \%$ for clipping; and 100\% for cerebral bypass. Cranial nerve palsy, transient or permanent, was significantly higher with open surgical techniques (64\% open treatment vs. 13\% endovascular treatment, $p=0.001)$. Overall, the FDS group had similar results to open technique with significantly lower complication rates.

\section{FDS vs. FDS-assisted coil embolization (FDS-CE)}

While FDS and traditional stents are grossly similar, the modulation of aneurysm flow dynamics adds an additional property to facilitate aneurysm occlusion in stent-assisted coiling techniques ${ }^{56)}$. Lin et al. ${ }^{72)}$ compared outcomes for FDS alone and FDS-CE for 104 aneurysms. In their institution, the coils are used as a scaffold to buttress the aneurysm dome and occlusion is reliant on aneurysm flow modulation by the FDS. This is in contrast to the dense packing needed in primary coil embolization techniques. The FDS-CE technique resulted in significantly higher complete occlusion rates $(93.1 \%$ vs. $74.4 \%$, $p=0.03)$ and lower retreatment rates $(3.4 \%$ vs. $16.0 \%, p=0.05)$ than stand-alone FDS. Five patients experienced periproce- 
dural complications, two in the FDS group and three in the FDS-CE group. In a series of 28 patients, Nossek et al. ${ }^{86}$ evaluated a FDS-CE technique employing more traditional dense coiling supported by the FDS. With this technique, the authors reported a complete occlusion in all 28 patients on final angiographic follow-up. While the authors reported no radiographic evidence of ischemia, other studies have identified increased complications with FDS-CE techniques. Park et al. ${ }^{88)}$ compared complications for FDS alone versus FDS-CE from the International Retrospective Study of Pipeline Embolization Device (IntrePED) dataset. Among 793 candidate cases, complication rates between those aneurysms treated by FDS and FDS-CE were not significantly different (7.8\% FDS vs. $12.5 \%$ FDS-CE, $p=0.13$ ). The hypothesized that the increased manipulations and intracranial procedure time of FDS-CE technique may explain the increased complication rate.

\section{Single FDS vs. multiple overlapping or telescop- ing FDS}

Most FDS have metal surface area coverage similar to the PED/PFED, or $30-35 \%$ in typical clinical applications. Theoretically, the use of multiple overlapping FDS would result in higher metal surface area coverage and further restriction of aneurysm blood flow, thereby increasing intra-aneurysmal thrombosis and occlusion. However, deployment of multiple overlapping FDS increases the number of endovascular manipulations and would lead to higher risk of complications. Chalouhi et al. ${ }^{19)}$ compared outcomes and complication among 158 patients undergoing treatment with either single $(n=126)$ or multiple $(n=52)$ FDS. While the rates of complete aneurysm occlusion were comparable (84\% single FDS vs. $87 \%$ multiple FDS, $p=0.8$ ) complication rates were significantly higher in the multiple FDS group (5\% single FDS vs. $15 \%$ multiple FDS, $p=0.03$ ). Moreover, the use of an additional FDS was found to be an independent predictor of procedural complications without a decrease in retreatment. These occlusion and complication results are similar to other FDS series ${ }^{14)}$. Kabbasch et al. ${ }^{57)}$ published a single center retrospective observational study of single FDS or multiple FDS treatment, with 121 FDS placed, to treat 58 aneurysms. Both the mean aneurysm size and mean neck diameter were significantly larger in the multiple FDS group $(p<0.05)$. In spite of this, the multiple FDS group had a significantly higher complete occlusion rate ( $93 \%$ multiple FDS vs. $60 \%$ single FDS, $p=0.01$ ) while complication rates were not significantly different.

There are several confounders that complicate interpretation of these varied clinical series. In Chalouhi et al. ${ }^{19)}$ the multiple FDS group included more high-risk patients; a higher median patient age; larger mean aneurysm size; more posterior circulation and distal circulation aneurysms; and more non-saccular aneurysms. All of these factors have been associated with higher complication rates. Additionally, $11 \%$ of single FDS and $6 \%$ of multiple FDS patients underwent adjunctive coiling of the aneurysm. In comparison, Kabbasch's study excluded aneurysms that had either been previously treated with coiling or that underwent adjunctive coil embolization, treatment aneurysm and adjunctive coil cases ${ }^{577}$. These differences in confounding risk factors may explain the conflicting results $^{19}$. Taken together, these studies suggest the multiple FDS technique may improve occlusion in complex aneurysms but must be weighed against likely higher complication rates.

\section{COMPLICATIONS IN ANEURYSMS TREATED WITH FDS}

As previously outlined, the complication rates for aneurysms treated with FDS are comparable to traditional coil embolization in both individual series and head-to-head comparison. Furthermore, it is often the case that FDS in these series may be used to treat aneurysms of higher complexity, with higher proportions of independent risk factors for complications ${ }^{2,12,14)}$. Several studies have detailed the complications encountered when FDS were used to treat aneurysms in detail. In their meta-analysis published in 2017, Zhou et al. ${ }^{122}$ analyzed 60 studies comprised of 3125 patients treated with FDS. The overall complication rate was $17.0 \%$. Complications were significantly higher when FDS were used to treat ruptured aneurysms (30.6\% ruptured vs. $14.6 \%$ unruptured, $p<0.05$ ). When comparing anterior and posterior circulation aneurysms treated with FDS, the complication rate for posterior circulation aneurysms was significantly higher (44.7\%). Lin et al. ${ }^{71)}$ analyzed ruptured aneurysms treated with FDS at multiple United States centers. While they found a complete occlusion rate of $78.3 \%$, the procedural complication rate was $19.2 \%$ and $11.2 \%$ of patients were deceased at hospital discharge. The IntrePED trial included long-term follow up with neurologic morbidity and mortality rate of $8.4 \%$. In their sub- 
group analysis of morbidity and mortality by aneurysm size and location, anterior circulation aneurysms $<10 \mathrm{~mm}$ had the lowest risk (4.8\%) while posterior circulation aneurysms had the highest complication rates $(16.4 \%)^{58)}$. Brinjikji et al. ${ }^{13)}$ also evaluated this IntrePED dataset, focusing on ischemic complications following FDS use. Ischemic complications were significantly higher with aneurysms of the middle cerebral artery territory; fusiform aneurysms; and giant aneurysms $(>25$ $\mathrm{mm}$ ). Aneurysm neck diameter was also found to be significantly larger in the subgroup with ischemic complications.

While many studies focused on immediate perioperative complications of FDS use, Cohen et al. ${ }^{25)}$ sought to characterize delayed complications after FDS for treatment of intracranial aneurysms. Progressive in-stent stenosis was documented in $36 \%$, of which only $15 \%$ were symptomatic, and was identified as early as 2 months post-procedure. Vedantam et al. ${ }^{118)}$ reported on carotid branch occlusion following FDS deployment in 49 patients. Three patients were found to have ICA branch occlusion and were asymptomatic in all cases. Furthermore, the number of FDS deployed was not significantly associated with in-stent stenosis; branch vessels occlusion; visual symptoms or motor deficits. They also found that symptomatic ischemic complications were more common in the 30-day immediately following FDS placement; this led the authors to hypothesize that gradual branch occlusion was compensated by adequate existing or neo-collateral circulation. Ischemic complications in the posterior circulation are more often symptomatic due to the smaller parent vessel diameter and relatively dense perforating artery supply arising from these vessels compared to the anterior circulation. Parent artery occlusion is a well-documented and dreaded complication of FDS deployment $22,66,87,96,97)$. Asymptomatic parent vessel occlusion is frequently associated with anterior circulation aneurysms ${ }^{94)}$. In contrast, parent artery occlusion in the posterior circulation is often associated with significant morbidity and/or mortality ${ }^{95)}$.

A common theme across studies is the association of parent artery occlusion or in-stent stenosis with discontinuation of antiplatelet agents ${ }^{6,10,41,63,79)}$. Accordingly, FDS demands strict attention to DAPT and screening for clopidogrel non-responders - platelet function testing can be a meaningful adjunct in the later task $\mathrm{k}^{40)}$. Thoughtful planning and monitoring of DAPT is of particular importance in posterior circulation FDS cases. Tan et al. ${ }^{110)}$ found that among 74 patients treated with FDS, P2Y12 reaction units $(\mathrm{PRU})>208$ was associated with higher rates symptomatic stroke, though the difference was non-significant. Delgado Almandoz et al. ${ }^{36)}$ similarly reported that under-response to clopidogrel was associated with increased symptomatic stroke after FDS deployment. On the other hand, hyper-responsiveness to clopidogrel by PRU was associated with higher rates of spontaneous hemorrhage in Goh et al. ${ }^{45)}$ and the rates of spontaneous hemorrhage were concordant with Delgado Almandoz et al. ${ }^{36)}$.

The major complications of FDS deployment include symptomatic ipsilateral ischemic stroke; intraparenchymal hemorrhage; and peri-procedural subarachnoid hemorrhage (SAH) secondary to aneurysm rupture ${ }^{32)}$. Early in FDS development particular emphasis was placed on periprocedural SAH due to the independent morbidity and mortality of SAH. One large meta-analysis in 2013 found 4\% of early PED cases were complicated by delayed SAH and this was significantly associated with large or giant aneurysms. Late delayed aneurysm rupture (>1-month post procedure) was rare, representing only $2 \%$ of postprocedural SAH ${ }^{14)}$. Rouchaud et al. ${ }^{100)}$ reviewed 53 studies of FDS placement to identify 81 cases of delayed hemorrhage. Aneurysms were located on the ICA in $75 \%$ and $46.3 \%$ of cases were giant aneurysms. These findings may be confounded by the IFU for PED/PFED that selects for large or giant anterior circulation aneurysms, predominantly of the ICA. The mechanisms of delayed hemorrhage remain unclear. Several hypotheses have been put forward, including transiently increased intra-aneurysmal pressure during or following FDS implantation ${ }^{17)}$; thrombus-associated autolysis of the aneurysm wall ${ }^{17,65)}$; increased hemodynamic strain on the aneurysm wall directly ${ }^{24)}$. Using computational hemodynamic analysis, Chong et al. ${ }^{24)}$ demonstrated significantly decreased jet flow through the aneurysm sac with marked stasis at the periphery of the aneurysm. Flow observation was increasingly difficult overtime consistent with progressive aneurysm thrombosis. In unsuccessful cases, however, jet flow pattern was unchanged by FDS deployment and may persist into the aneurysm. After considering these factors, several techniques have been advocated to avoid periprocedural aneurysm rupture, including adjunctive coil embolization and strict blood pressure control perioperatively ${ }^{68)}$. Nossek et al. ${ }^{86)}$ treated 27 patients with 28 aneurysms and used PED and partially dense coil packing (Raymond grade 2 or 3). One-year follow up angiography showed that 23 patients with 24 aneurysms $(85.2 \%)$ 
occluded completely. Because of low porosity of FDS, partial dense coil packing may be enough to prevent delayed aneurysm rupture following FDS treatment. Rather, Siddiqui et al. ${ }^{106)}$ reported acute FDS thrombosis after dense coil packing with FDS.

\section{FUTURE DIRECTIONS FOR FDS}

In the short interval since the PED was first introduced, FDS have been firmly entrenched as a powerful tool in the endovascular armamentarium. The IFU have been broadened and off-label use has systematically progressed to nearly all large vessel territories of the cerebrovascular circulation. As new FDS are developed, established FDS are refined, and delivery systems are improved the uses for FDS will only expand further. Researchers continue to work to optimize the mechanical characteristics of the FDS themselves, aiming to optimize deploy ability and efficacy. Recent advances like duallayered weave and new cell configurations target improved wall apposition, more uniform cell configuration, improved and uniform radial force, and improved delivery and resheathing. The FRED Jr (Microvention, Tustin, CA, USA) was recently introduced specifically to address the challenges of using FDS in small distal arteries ${ }^{82,93}$. While it retains the dual-layered construction of its namesake, it leverages a 36wire inner layer and 16-wire outer layer to facilitate use in vessels from $2-3 \mathrm{~mm}$ in diameter. Increased attention to DAPT and pooling of data will help to develop more rigorous guidelines for pre- and post-procedure DAPT while quantitative screening for non-responders with platelet function and clotting assays will guide personalized DAPT regimens for the individual patient. Additionally, new techniques to combat thrombosis may further reduce ischemic complications. For example, phosphorylcholine-a component of erythrocyte outer cell membrane-may resist platelet adhesion and promote intimal hyperplasia. These properties have been leveraged in Shield Technology ${ }^{\mathrm{TM}}$ (Medtronic) whereby a $3 \mathrm{~nm}$ layer of phosphorylcholine is covalently bound to the PED weave surface. In pre-clinical studies PED shield has been associated with reduced inflammation, reduced thrombosis, and increased early neointimal growth ${ }^{44,52,77)}$. Finally, further data on the safety of FDS and DAPT in acutely ruptured aneurysms is needed to inform further use in this sub-population of aneu- rysm patients. Surpass Evolve (Stryker Neurovascular) is the second generation of Surpass Streamline FDS. It has 52 wires made of cobalt-chromium and 12 wires made of platinumtungsten for fluoroscopic visibility ${ }^{103)}$. Surpass Evolve has fewer wires and the different braid angle compare to Surpass Streamline. These changes improve flexibility and wall apposition. The improved flexibility may enhance deliverability of the stent through the microcatheter. Surpass Streamline has a medium braid angle whereas Surpass Evolve has a higher braid angle. The higher braid angle is one of the important factors to improving vessel wall apposition. Despite Surpass Evolve having fewer wires, high braid angle maintains the same mesh density (pores per $\mathrm{mm}^{2}$ ) as Surpass Streamline. However, high braid angle may lead to more stent foreshortening then medium braid angle.

With expanded use for small to medium aneurysms and posterior circulation aneurysms, FDS technology is firmly entrenched as a powerful tool to treat challenging aneurysms, both primarily and as an adjunct to coil embolization. With the aforementioned advances, the ease of FDS deployment will improve and complication rates will be further minimized. This will only further establish FDS deployment as a key strategy in the treatment of cerebral aneurysms.

\section{CONFLICTS OF INTEREST}

No potential conflict of interest relevant to this article was reported.

\section{INFORMED CONSENT}

This type of study does not require informed consent.

\section{AUTHOR CONTRIBUTIONS}

\author{
Conceptualization : BLH, BTK \\ Data curation : DSS, ME \\ Methodology : DSS, BLH, BTK \\ Writing - original draft : DSS, CPC \\ Writing - review \& editing : BLH, BTK
}




\section{ORCID}

Dong-Seong Shin http://orcid.org/0000-0001-8633-202X

Christopher P. Carroll http://orcid.org/0000-0001-5833-7405

Mohammed Elghareeb http://orcid.org/0000-0002-0466-7684

Brian L. Hoh

http://orcid.org/0000-0002-4997-4469

Bum-Tae Kim

http://orcid.org/0000-0003-2646-8165

\section{- Acknowledgements}

This work was supported by Soonchunhyang University research fund.

\section{References}

1. Alderazi YJ, Shastri D, Kass-Hout T, Prestigiacomo CJ, Gandhi CD : Flow diverters for intracranial aneurysms. Stroke Res Treat 2014 : 415653, 2014

2. Arrese I, Sarabia R, Pintado R, Delgado-Rodriguez M : Flow-diverter devices for intracranial aneurysms: systematic review and meta-analysis. Neurosurgery 73 : 193-199; discussion 199-200, 2013

3. Becske T, Brinjikji W, Potts MB, Kallmes DF, Shapiro M, Moran CJ, et al. : Long-term clinical and angiographic outcomes following pipeline embolization device treatment of complex internal carotid artery aneurysms: five-year results of the pipeline for uncoilable or failed aneurysms trial. Neurosurgery $80: 40-48,2017$

4. Becske T, Kallmes DF, Saatci I, McDougall CG, Szikora I, Lanzino G, et al. : Pipeline for uncoilable or failed aneurysms: results from a multicenter clinical trial. Radiology 267 : 858-868, 2013

5. Becske T, Potts MB, Shapiro M, Kallmes DF, Brinjikji W, Saatci I, et al. : Pipeline for uncoilable or failed aneurysms: 3-year follow-up results. J Neurosurg $127: 81-88,2017$

6. Bender MT, Colby GP, Jiang B, Lin LM, Campos JK, Xu R, et al. : Flow diversion of posterior circulation cerebral aneurysms: a single-institution series of 59 cases. Neurosurgery $84:$ 206-216, 2019

7. Bender MT, Lin LM, Colby GP, Lubelski D, Huang J, Tamargo RJ, et al. : P2Y12 hyporesponse (PRU>200) is not associated with increased thromboembolic complications in anterior circulation pipeline. J Neurointerv Surg 9 : 978-981, 2017

8. Berge J, Biondi A, Machi P, Brunel H, Pierot L, Gabrillargues J, et al. : Flow-diverter silk stent for the treatment of intracranial aneurysms: 1-year follow-up in a multicenter study. AJNR Am J Neuroradiol 33 : 1150-1155, 2012

9. Bhogal P, Martinez Moreno R, Ganslandt O, Bäzner H, Henkes H, Perez $M A$ : Use of flow diverters in the treatment of unruptured saccular aneurysms of the anterior cerebral artery. J Neurointerv Surg 9 : 283289, 2017

10. Bhogal P, Pérez MA, Ganslandt O, Bazner H, Henkes H, Fischer S : Treat- ment of posterior circulation non-saccular aneurysms with flow diverters: a single-center experience and review of 56 patients. J Neurointerv Surg $9: 471-481,2017$

11. Biondi A, Janardhan V, Katz JM, Salvaggio K, Riina HA, Gobin YP : Neuroform stent-assisted coil embolization of wide-neck intracranial aneurysms: strategies in stent deployment and midterm follow-up. Neurosurgery 61 : 460-468; discussion 468-469, 2007

12. Briganti F, Leone G, Marseglia M, Mariniello G, Caranci F, Brunetti A, et al. : Endovascular treatment of cerebral aneurysms using flow-diverter devices: a systematic review. Neuroradiol J 28 : 365-375, 2015

13. Brinjikji W, Lanzino G, Cloft HJ, Siddiqui AH, Boccardi E, Cekirge S, et al. : Risk factors for ischemic complications following pipeline embolization device treatment of intracranial aneurysms: results from the IntrePED study. AJNR Am J Neuroradiol 37 : 1673-1678, 2016.

14. Brinjikji W, Murad MH, Lanzino G, Cloft HJ, Kallmes DF : Endovascular treatment of intracranial aneurysms with flow diverters: a meta-analysis. Stroke 44 : 442-447, 2013

15. Byrne JV, Beltechi R, Yarnold JA, Birks J, Kamran M : Early experience in the treatment of intra-cranial aneurysms by endovascular flow diversion: a multicentre prospective study. PLoS One 5 : e12492, 2010

16. Cagnazzo F, Cappucci M, Dargazanli C, Lefevre PH, Gascou G, Riquelme $C$, et al. : Treatment of distal anterior cerebral artery aneurysms with flow-diverter stents: a single-center experience. AJNR Am J Neuroradiol 39 : 1100-1106, 2018

17. Cebral JR, Mut F, Raschi M, Scrivano E, Ceratto R, Lylyk P, et al. : Aneurysm rupture following treatment with flow-diverting stents: computational hemodynamics analysis of treatment. AJNR Am J Neuroradiol $32: 27-33,2011$

18. Chalouhi N, Starke RM, Yang S, Bovenzi CD, Tjoumakaris S, Hasan D, et al. : Extending the indications of flow diversion to small, unruptured, saccular aneurysms of the anterior circulation. Stroke 45 : 54-58, 2014

19. Chalouhi N, Tjoumakaris S, Phillips JL, Starke RM, Hasan D, Wu C, et al. : A single pipeline embolization device is sufficient for treatment of intracranial aneurysms. AJNR Am J Neuroradiol 35 : 1562-1566, 2014

20. Chalouhi N, Tjoumakaris S, Starke RM, Gonzalez LF, Randazzo C, Hasan $D$, et al. : Comparison of flow diversion and coiling in large unruptured intracranial saccular aneurysms. Stroke 44 : 2150-2154, 2013

21. Chalouhi N, Zanaty M, Whiting A, Yang S, Tjoumakaris S, Hasan D, et al. : Safety and efficacy of the pipeline embolization device in 100 small intracranial aneurysms. J Neurosurg 122 : 1498-1502, 2015

22. Chitale R, Gonzalez LF, Randazzo C, Dumont AS, Tjoumakaris S, Rosenwasser $R$, et al. : Single center experience with pipeline stent: feasibility, technique, and complications. Neurosurgery 71 : 679-691; discussion 691, 2012

23. Chiu AH, Cheung AK, Wenderoth JD, De Villiers L, Rice H, Phatouros CC, et al. : Long-term follow-up results following elective treatment of unruptured intracranial aneurysms with the pipeline embolization device. AJNR Am J Neuroradiol 36 : 1728-1734, 2015

24. Chong W, Zhang Y, Qian Y, Lai L, Parker G, Mitchell K : Computational hemodynamics analysis of intracranial aneurysms treated with flow diverters: correlation with clinical outcomes. AJNR Am J Neuroradiol 
$35: 136-142,2014$

25. Cohen JE, Gomori JM, Moscovici S, Leker RR, Itshayek E : Delayed complications after flow-diverter stenting: reactive in-stent stenosis and creeping stents. J Clin Neurosci 21 : 1116-1122, 2014

26. Colby GP, Bender MT, Lin LM, Beaty N, Huang J, Tamargo RJ, et al. : Endovascular flow diversion for treatment of anterior communicating artery region cerebral aneurysms: a single-center cohort of 50 cases. J Neurointerv Surg 9 : 679-685, 2017

27. Colby GP, Lin LM, Caplan JM, Jiang B, Michniewicz B, Huang J, et al. : Flow diversion of large internal carotid artery aneurysms with the surpass device: impressions and technical nuance from the initial North American experience. J Neurointerv Surg 8 : 279-286, 2016

28. Colby GP, Lin LM, Gomez JF, Paul AR, Huang J, Tamargo RJ, et al. : Immediate procedural outcomes in 35 consecutive pipeline embolization cases: a single-center, single-user experience. J Neurointerv Surg 5 : 237-246, 2013

29. Colby GP, Lin LM, Huang J, Tamargo RJ, Coon AL : Utilization of the Navien distal intracranial catheter in 78 cases of anterior circulation aneurysm treatment with the pipeline embolization device. J Neurointerv Surg 5 Suppl 3 : iii16-iii21, 2013

30. Colby GP, Lin LM, Nundkumar N, Jiang B, Huang J, Tamargo RJ, et al. : Radiation dose analysis of large and giant internal carotid artery aneurysm treatment with the pipeline embolization device versus traditional coiling techniques. J Neurointerv Surg 7 : 380-384, 2015

31. Connolly ES Jr : International study of unruptured intracranial aneurysms. J Neurosurg 121 : 1022-1023, 2014

32. Cruz JP, Chow M, O'Kelly C, Marotta B, Spears J, Montanera W, et al. : Delayed ipsilateral parenchymal hemorrhage following flow diversion for the treatment of anterior circulation aneurysms. AJNR Am J Neuroradiol 33 : 603-608, 2012

33. Darsaut TE, Bing F, Salazkin I, Gevry G, Raymond J : Flow diverters can occlude aneurysms and preserve arterial branches: a new experimental model. AJNR Am J Neuroradiol 33 : 2004-2009, 2012

34. De Vries J, Boogaarts J, Van Norden A, Wakhloo AK : New generation of flow diverter (surpass) for unruptured intracranial aneurysms: a prospective single-center study in 37 patients. Stroke 44 : 1567-1577, 2013

35. Delgado Almandoz JE, Crandall BM, Scholz JM, Fease JL, Anderson $\mathrm{RE}$, Kadkhodayan $\mathrm{Y}$, et al. : Last-recorded P2Y12 reaction units value is strongly associated with thromboembolic and hemorrhagic complications occurring up to 6 months after treatment in patients with cerebral aneurysms treated with the pipeline embolization device. AJNR Am J Neuroradiol 35 : 128-135, 2014

36. Delgado Almandoz JE, Kadkhodayan Y, Crandall BM, Scholz JM, Fease $J$, Tubman DE : Variability in initial response to standard clopidogrel therapy, delayed conversion to clopidogrel hyper-response, and associated thromboembolic and hemorrhagic complications in patients undergoing endovascular treatment of unruptured cerebral aneurysms. J Neurointerv Surg 6 : 767-773, 2014

37. Di Maria F, Pistocchi $S$, Clarençon F, Bartolini B, Blanc R, Biondi A, et al. : Flow diversion versus standard endovascular techniques for the treat- ment of unruptured carotid-ophthalmic aneurysms. AJNR Am J Neuroradiol $36: 2325-2330,2015$

38. Diaz O, Gist TL, Manjarez G, Orozco F, Almeida R : Treatment of 14 intracranial aneurysms with the FRED system. J Neurointerv Surg 6 : 614-617, 2014

39. Ferns SP, Sprengers ME, van Rooij WJ, Rinkel GJ, van Rijn JC, Bipat S, et al. : Coiling of intracranial aneurysms: a systematic review on initial occlusion and reopening and retreatment rates. Stroke 40 : e523-e529, 2009

40. Fifi JT, Brockington C, Narang J, Leesch W, Ewing SL, Bennet H, et al. : Clopidogrel resistance is associated with thromboembolic complications in patients undergoing neurovascular stenting. AJNR Am J Neuroradiol 34 : 716-720, 2013

41. Fiorella D, Hsu D, Woo HH, Tarr RW, Nelson PK : Very late thrombosis of a pipeline embolization device construct: case report. Neurosurgery 67(3 Suppl Operative) : onsE313-onsE314; discussion onsE314, 2010

42. Fiorella D, Lylyk P, Szikora I, Kelly ME, Albuquerque FC, McDougall CG, et al. : Curative cerebrovascular reconstruction with the pipeline embolization device: the emergence of definitive endovascular therapy for intracranial aneurysms. J Neurointerv Surg 1 : 56-65, 2009

43. Fiorella D, Woo HH, Albuquerque FC, Nelson PK : Definitive reconstruction of circumferential, fusiform intracranial aneurysms with the pipeline embolization device. Neurosurgery 62 : 1115-1120; discussion 11201121,2008

44. Girdhar G, Andersen A, Pangerl E, Jahanbekam R, Ubl S, Nguyen K, et al. : Thrombogenicity assessment of pipeline flex, pipeline shield, and FRED flow diverters in an in vitro human blood physiological flow loop model. J Biomed Mater Res A 106 : 3195-3202, 2018

45. Goh C, Churilov L, Mitchell P, Dowling R, Yan B : Clopidogrel hyperresponse and bleeding risk in neurointerventional procedures. AJNR Am J Neuroradiol 34 : 721-726, 2013

46. Gonzalez NR, Duckwiler G, Jahan R, Murayama Y, Vinuela F : Challenges in the endovascular treatment of giant intracranial aneurysms. Neurosurgery 62 : 1324-1335, 2008

47. Griessenauer CJ, Ogilvy CS, Foreman PM, Chua MH, Harrigan MR, Stapleton CJ, et al. : Pipeline embolization device for small paraophthalmic artery aneurysms with an emphasis on the anatomical relationship of ophthalmic artery origin and aneurysm. J Neurosurg 125 : 1352-1359, 2016

48. Gruber A, Killer M, Bavinzski G, Richling B : Clinical and angiographic results of endosaccular coiling treatment of giant and very large intracranial aneurysms: a 7-year, single-center experience. Neurosurgery 45 : 793-803; discussion 803-804, 1999

49. Guglielmi G, Viñuela F, Dion J, Duckwiler G : Electrothrombosis of saccular aneurysms via endovascular approach. Part 2: preliminary clinical experience. J Neurosurg $75: 8-14,1991$

50. Guglielmi G, Viñuela F, Duckwiler G, Dion J, Lylyk P, Berenstein A, et al. : Endovascular treatment of posterior circulation aneurysms by electrothrombosis using electrically detachable coils. J Neurosurg 77 : 515 524, 1992

51. Guglielmi G, Viñuela F, Sepetka I, Macellari V : Electrothrombosis of 
saccular aneurysms via endovascular approach. Part 1: electrochemical basis, technique, and experimental results. J Neurosurg 75 : 1-7, 1991

52. Hagen MW, Girdhar G, Wainwright J, Hinds MT : Thrombogenicity of flow diverters in an ex vivo shunt model: effect of phosphorylcholine surface modification. J Neurointerv Surg 9 : 1006-1011, 2017

53. Hanel RA, Kallmes DF, Lopes DK, Nelson PK, Siddiqui A, Jabbour P, et al. : Prospective study on embolization of intracranial aneurysms with the pipeline device: the PREMIER study 1 year results. J Neurointerv Surg 12 : 62-66, 2020

54. Health Insurance Review \& Assessment Service : Notification of Ministtry of health and welfare: Flow diverter stent embolization device (No. 2014-191). Available at : http://www.hira.or.kr/ bbsDummy.do?brdBItNo=5482\&brdScnBltNo=5484\&pgmid=HIR AA020002000100

55. International Study of Unruptured Intracranial Aneurysms Investigators : Unruptured intracranial aneurysms--risk of rupture and risks of surgical intervention. N Engl J Med 339 : 1725-1733, 1998

56. Jo KI, Yang NR, Jeon P, Kim KH, Hong SC, Kim JS : Treatment outcomes with selective coil embolization for large or giant aneurysms : prognostic implications of incomplete occlusion. J Korean Neurosurg Soc 61 : 19-27, 2018

57. Kabbasch C, Mpotsaris A, Behme D, Dorn F, Stavrinou P, Liebig T : Pipeline embolization device for treatment of intracranial aneurysms-the more, the better? A single-center retrospective observational study. J Vasc Interv Neurol 9 : 14-20, 2016

58. Kallmes DF, Hanel R, Lopes D, Boccardi E, Bonafé A, Cekirge S, et al. : International retrospective study of the pipeline embolization device: a multicenter aneurysm treatment study. AJNR Am J Neuroradiol 36 : 108-115, 2015

59. Karsy M, Guan J, Brock AA, Amin A, Park MS : Emerging technologies in flow diverters and stents for cerebrovascular diseases. Curr Neurol Neurosci Rep 17 : 96, 2017

60. Kim BM, Shin YS, Baik MW, Lee DH, Jeon P, Baik SK, et al. : Pipeline embolization device for large/giant or fusiform aneurysms: an initial multicenter experience in Korea. Neurointervention 11 : 10-17, 2016

61. Kim LJ, Tariq F, Levitt M, Barber J, Ghodke B, Hallam DK, et al. : Multimodality treatment of complex unruptured cavernous and paraclinoid aneurysms. Neurosurgery 74 : 51-61; discussion 61; quiz 61, 2014

62. Kim TG, Kwon O, Shin YS, Sung JH, Koh JS, Kim BT : Endovascular treatments performed collaboratively by the Society of Korean Endovascular Neurosurgeons members : a nationwide multicenter survey. J Korean Neurosurg Soc 62 : 502-518, 2019

63. Klisch J, Turk A, Turner R, Woo HH, Fiorella D : Very late thrombosis of flow-diverting constructs after the treatment of large fusiform posterior circulation aneurysms. AJNR Am J Neuroradiol 32 : 627-632, 2011

64. Kocer N, Islak C, Kizilkilic O, Kocak B, Saglam M, Tureci E : Flow redirection endoluminal Device in treatment of cerebral aneurysms: initial experience with short-term follow-up results. J Neurosurg 120 : 11581171, 2014

65. Kulcsár Z, Houdart E, Bonafé A, Parker G, Millar J, Goddard AJ, et al. : Intra-aneurysmal thrombosis as a possible cause of delayed aneurysm rupture after flow-diversion treatment. AJNR Am J Neuroradiol 32 : 20-25, 2011

66. Lanzino G, Crobeddu E, Cloft HJ, Hanel R, Kallmes DF : Efficacy and safety of flow diversion for paraclinoid aneurysms: a matched-pair analysis compared with standard endovascular approaches. AJNR Am J Neuroradiol 33 : 2158-2161, 2012

67. Le Quellec S, Bordet JC, Negrier C, Dargaud Y : Comparison of current platelet functional tests for the assessment of aspirin and clopidogrel response. A review of the literature. Thromb Haemost 116 : 638-650, 2016

68. Lee JY, Cho YD, Kang HS, Han MH : Healing of aneurysm after treatment using flow diverter stent : histopathological study in experimental canine carotid side wall aneurysm. J Korean Neurosurg Soc 63 : 3444, 2020

69. Lin LM, Colby GP, Huang J, Tamargo RJ, Coon AL : Ultra-distal largebore intracranial access using the hyperflexible Navien distal intracranial catheter for the treatment of cerebrovascular pathologies: a technical note. J Neurointerv Surg 6 : 301-307, 2014

70. Lin LM, Colby GP, Jiang B, Uwandu C, Huang J, Tamargo RJ, et al. : Classification of cavernous internal carotid artery tortuosity: a predictor of procedural complexity in pipeline embolization. J Neurointerv Surg 7 : 628-633, 2015

71. Lin N, Brouillard AM, Keigher KM, Lopes DK, Binning MJ, Liebman KM, et al. : Utilization of Pipeline embolization device for treatment of ruptured intracranial aneurysms: US multicenter experience. J Neurointerv Surg 7 : 808-815, 2015

72. Lin N, Brouillard AM, Krishna C, Mokin M, Natarajan SK, Sonig A, et al. : Use of coils in conjunction with the pipeline embolization device for treatment of intracranial aneurysms. Neurosurgery 76 : 142-149, 2015

73. Lin N, Lanzino G, Lopes DK, Arthur AS, Ogilvy CS, Ecker RD, et al. : Treatment of distal anterior circulation aneurysms with the pipeline embolization device: a US multicenter experience. Neurosurgery 79 : 1422, 2016

74. Lylyk P, Miranda C, Ceratto R, Ferrario A, Scrivano E, Luna HR, et al. : Curative endovascular reconstruction of cerebral aneurysms with the pipeline embolization device: the Buenos Aires experience. Neurosurgery 64 : 632-642; discussion 642-643; quiz N6, 2009

75. Mahboobani NR, Chong WH, Lam SS, Siu JC, Tan CB, Wong YC : Treatment of intracranial aneurysms with flow re-direction endoluminal device - a single centre experience with short-term follow-up results. Neurointervention 12 : 11-19, 2017

76. Martínez-Galdámez M, Gil A, Caniego JL, Gonzalez E, Bárcena E, Perez S, et al. : Preliminary experience with the pipeline flex embolization device: technical note. J Neurointerv Surg 7 : 748-751, 2015

77. Martínez-Galdámez M, Lamin SM, Lagios KG, Liebig T, Ciceri EF, Chapot $R$, et al. : Treatment of intracranial aneurysms using the pipeline flex embolization device with shield technology: angiographic and safety outcomes at 1-year follow-up. J Neurointerv Surg 11 : 396-399, 2019

78. Martínez-Galdámez $M$, Pérez $S$, Vega $A$, Ruiz $P$, Caniego JL, Bárcena $E$, et al. : Endovascular treatment of intracranial aneurysms using the pipe- 
line flex embolization device: a case series of 30 consecutive patients. J Neurointerv Surg 8 : 396-401, 2016

79. Meckel S, McAuliffe W, Fiorella D, Taschner CA, Phatouros C, Phillips TJ, et al. : Endovascular treatment of complex aneurysms at the vertebrobasilar junction with flow-diverting stents: initial experience. Neurosurgery 73 : 386-394, 2013

80. Meyers PM, Coon AL, Kan PT, Wakhloo AK, Hanel RA : SCENT trial. Stroke 50 : 1473-1479, 2019

81. Möhlenbruch MA, Herweh C, Jestaedt L, Stampfl S, Schönenberger S, Ringleb PA, et al. : The FRED flow-diverter stent for intracranial aneurysms: clinical study to assess safety and efficacy. AJNR Am J Neuroradiol 36 : 1155-1161, 2015

82. Möhlenbruch MA, Kizilkilic O, Killer-Oberpfalzer M, Baltacioglu F, Islak C, Bendszus M, et al. : Multicenter experience with FRED Jr flow redirection endoluminal device for intracranial aneurysms in small arteries. AJNR Am J Neuroradiol 38 : 1959-1965, 2017

83. Moret J, Cognard C, Weill A, Castaings L, Rey A : The "remodelling technique" in the treatment of wide neck intracranial aneurysms. angiographic results and clinical follow-up in 56 cases. Interv Neuroradiol 3 : 21-35, 1997

84. Murthy SB, Shah J, Mangat HS, Stieg P : Treatment of intracranial aneurysms with pipeline embolization device: newer applications and technical advances. Curr Treat Options Neurol 18 : 16, 2016

85. Nelson PK, Lylyk P, Szikora I, Wetzel SG, Wanke I, Fiorella D : The pipeline embolization device for the intracranial treatment of aneurysms trial.

AJNR Am J Neuroradiol 32 : 34-40, 2011

86. Nossek E, Chalif DJ, Chakraborty S, Lombardo K, Black KS, Setton A : Concurrent use of the pipeline embolization device and coils for intracranial aneurysms: technique, safety, and efficacy. J Neurosurg 122 : 904-911, 2015

87. Park MS, Albuquerque FC, Nanaszko M, Sanborn MR, Moon K, Abla $A A$, et al. : Critical assessment of complications associated with use of the pipeline embolization device. J Neurointerv Surg 7 : 652-659, 2015

88. Park MS, Kilburg C, Taussky P, Albuquerque FC, Kallmes DF, Levy El, et al. : Pipeline embolization device with or without adjunctive coil embolization: analysis of complications from the IntrePED registry. AJNR Am J Neuroradiol 37 : 1127-1131, 2016

89. Patel PD, Chalouhi N, Atallah E, Tjoumakaris S, Hasan D, Zarzour $H$, et al. : Off-label uses of the Pipeline embolization device: a review of the literature. Neurosurg Focus 42 : E4, 2017

90. Pereira VM, Kelly M, Vega P, Murias E, Yilmaz H, Erceg G, et al. : New pipeline flex device: initial experience and technical nuances. J Neurointerv Surg 7 : 920-925, 2015

91. Petr O, Brinjikji W, Cloft H, Kallmes DF, Lanzino G : Current trends and results of endovascular treatment of unruptured intracranial aneurysms at a single institution in the flow-diverter era. AJNR Am J Neuroradiol 37 : 1106-1113, 2016

92. Petr O, Coufalová L, Bradáč O, Rehwald R, Glodny B, Beneš V : Safety and efficacy of surgical and endovascular treatment for distal anterior cerebral artery aneurysms: a systematic review and meta-analysis.
World Neurosurg 100 : 557-566, 2017

93. Pierot $L$, Spelle L, Berge J, Januel AC, Herbreteau D, Aggour M, et al. : Feasibility, complications, morbidity, and mortality results at 6 months for aneurysm treatment with the flow re-direction endoluminal device: report of SAFE study. J Neurointerv Surg 10 : 765-770, 2018

94. Pistocchi S, Blanc R, Bartolini B, Piotin M : Flow diverters at and beyond the level of the circle of willis for the treatment of intracranial aneurysms. Stroke 43 : 1032-1038, 2012

95. Potts MB, Shapiro M, Zumofen DW, Raz E, Nossek E, DeSousa KG, et al. : Parent vessel occlusion after pipeline embolization of cerebral aneurysms of the anterior circulation. J Neurosurg 127 : 1333-1341, 2017

96. Puffer RC, Kallmes DF, Cloft HJ, Lanzino G : Patency of the ophthalmic artery after flow diversion treatment of paraclinoid aneurysms. J Neurosurg $116: 892-896,2012$

97. Puffer RC, Piano M, Lanzino G, Valvassori L, Kallmes DF, Quilici L, et al. : Treatment of cavernous sinus aneurysms with flow diversion: results in 44 patients. AJNR Am J Neuroradiol 35 : 948-951, 2014

98. Rajah G, Narayanan S, Rangel-Castilla L : Update on flow diverters for the endovascular management of cerebral aneurysms. Neurosurg Focus 42 : E2, 2017

99. Rouchaud A, Brinjikji W, Cloft HJ, Kallmes DF : Endovascular treatment of ruptured blister-like aneurysms: a systematic review and meta-analysis with focus on deconstructive versus reconstructive and flow-diverter treatments. AJNR Am J Neuroradiol 36 : 2331-2339, 2015

100. Rouchaud A, Brinjikji W, Lanzino G, Cloft HJ, Kadirvel R, Kallmes DF : Delayed hemorrhagic complications after flow diversion for intracranial aneurysms: a literature overview. Neuroradiology 58 : 171-177, 2016

101. Saatci I, Yavuz K, Ozer C, Geyik S, Cekirge HS : Treatment of intracranial aneurysms using the pipeline flow-diverter embolization device: a single-center experience with long-term follow-up results. AJNR Am J Neuroradiol 33 : 1436-1446, 2012

102. Sadasivan C, Cesar L, Seong J, Rakian A, Hao Q, Tio FO, et al. : An original flow diversion device for the treatment of intracranial aneurysms: evaluation in the rabbit elastase-induced model. Stroke 40 : 952-958, 2009

103. Sadasivan C, Fiorella D : Preliminary in vitro angiographic comparison of the flow diversion behavior of evolve and pipeline devices. J Neurointerv Surg, 2019 [Epub ahead of print]

104. Schievink WI, Wijdicks EF, Piepgras DG, Chu CP, O'Fallon WM, Whisnant JP : The poor prognosis of ruptured intracranial aneurysms of the posterior circulation. J Neurosurg 82 : 791-795, 1995

105. Shapiro M, Becske T, Sahlein D, Babb J, Nelson PK : Stent-supported aneurysm coiling: a literature survey of treatment and follow-up. AJNR Am J Neuroradiol 33 : 159-163, 2012

106. Siddiqui AH, Kan P, Abla AA, Hopkins LN, Levy El : Complications after treatment with pipeline embolization for giant distal intracranial aneurysms with or without coil embolization. Neurosurgery 71 : E509E513; discussion E513, 2012

107. Sönmez Ö, Brinjikji W, Murad MH, Lanzino G : Deconstructive and reconstructive techniques in treatment of vertebrobasilar dissecting aneurysms: a systematic review and meta-analysis. AJNR Am J Neu- 
roradiol 36 : 1293-1298, 2015

108. Steinberg GK, Drake CG, Peerless SJ : Deliberate basilar or vertebral artery occlusion in the treatment of intracranial aneurysms. Immediate results and long-term outcome in 201 patients. J Neurosurg 79 : 161173, 1993

109. Sturiale CL, Brinjikji W, Murad MH, Cloft HJ, Kallmes DF, Lanzino G : Endovascular treatment of distal anterior cerebral artery aneurysms: singlecenter experience and a systematic review. AJNR Am J Neuroradiol 34 : 2317-2320, 2013

110. Tan LA, Keigher KM, Munich SA, Moftakhar R, Lopes DK : Thromboembolic complications with pipeline embolization device placement: impact of procedure time, number of stents and pre-procedure P2Y12 reaction unit (PRU) value. J Neurointerv Surg 7 : 217-221, 2015

111. Tanweer O, Raz E, Brunswick A, Zumofen D, Shapiro M, Riina HA, et al. : Cavernous carotid aneurysms in the era of flow diversion: a need to revisit treatment paradigms. AJNR Am J Neuroradiol 35 : 2334-2340, 2014

112. Taschner CA, Vedantham S, de Vries J, Biondi A, Boogaarts J, Sakai N, et al. : Surpass flow diverter for treatment of posterior circulation aneurysms. AJNR Am J Neuroradiol 38 : 582-589, 2017

113. Texakalidis P, Bekelis K, Atallah E, Tjoumakaris $S$, Rosenwasser RH, Jabbour $P$ : Flow diversion with the pipeline embolization device for patients with intracranial aneurysms and antiplatelet therapy: a systematic literature review. Clin Neurol Neurosurg 161 : 78-87, 2017

114. U.S. Food and Drug Administration : Instructions for Use (IFU): PipelineTM Embolization Device. Available at : https://www.ac-
cessdata.fda.gov/cdrh_docs/pdf10/P100018c.pdf

115. U.S. Food and Drug Administration : Surpass Streamline Flow Diverter - P170024. Available at : https://www.fda.gov/medical-devices/ recently-approved-devices/surpass-streamline-flow-diverter-p170024

116. U.S. Food and Drug Administration: Pipeline Flex Embolization Device - P100018/S015. Available at : https://www.fda.gov/medicaldevices/recently-approved-devices/pipeline-flex-embolization-devicep100018s015

117. van Rooij WJ, Sluzewski M : Endovascular treatment of large and giant aneurysms. AJNR Am J Neuroradiol 30 : 12-18, 2009

118. Vedantam A, Rao VY, Shaltoni HM, Mawad ME : Incidence and clinical implications of carotid branch occlusion following treatment of internal carotid artery aneurysms with the pipeline embolization device. Neurosurgery 76 : 173-178; discussion 178, 2015

119. Velioglu M, Kizilkilic O, Selcuk H, Kocak B, Tureci E, Islak C, et al. : Early and midterm results of complex cerebral aneurysms treated with silk stent. Neuroradiology 54 : 1355-1365, 2012

120. Yan Y, Zhu D, Tang H, Huang Q : Safety and efficacy of flow diverter treatment for aneurysm in small cerebral vessels: a systematic review and meta-analysis. World Neurosurgery 115 : 54-64, 2018

121. Yao X, Ma J, Li H, Shen H, Lu X, Chen G : Safety and efficiency of flow diverters for treating small intracranial aneurysms: a systematic review and meta-analysis. J Int Med Res 45 : 11-21, 2017

122. Zhou G, Su M, Yin YL, Li MH : Complications associated with the use of flow-diverting devices for cerebral aneurysms: a systematic review and meta-analysis. Neurosurg Focus 42 : E17, 2017 